INTERVENTIONAL CARDIOLOGY AND SURGERY

\title{
Routine sirolimus eluting stent implantation for unselected in- stent restenosis: insights from the rapamycin eluting stent evaluated at Rotterdam cardiology hospital (RESEARCH) registry
}

\author{
F Saia, P A Lemos, C A Arampatzis, A Hoye, M Degertekin, K Tanabe, G Sianos, P C Smits, \\ W J van der Giessen, P J de Feyter, R T van Domburg, P W Serruys
}

Heart 2004;90:1183-1188. doi: 10.1136/hrt.2003.025536

See end of article for
authors' affiliations
$\ldots \ldots \ldots \ldots \ldots \ldots \ldots . . . .$.
Correspondence to:
Professor Patrick W
Serruys, Erasmus MC,
Thoraxcentre, Kamer Bd
404, Dr Molewaterplein
40,3015 GD Rotterdam,
Netherlands;
p.w.j.c.serruys@
erasmusmc.nl
Accepted
17 December 2003

17 December 2003

\begin{abstract}
Objective: To assess the effectiveness of routine sirolimus eluting stent (SES) implantation for unselected patients with in-stent restenosis and to provide preliminary information about the angiographic outcome for lesion subgroups and for different in-stent restenosis patterns.

Design: Prospective, single centre registry.

Setting: Tertiary referral centre.

Patients: 44 consecutive patients (53 lesions) without previous brachytherapy who were treated with SES for in-stent restenosis were evaluated. Routine angiographic follow up was obtained at six months and the incidence of major adverse cardiovascular events was evaluated.

Results: At baseline, $42 \%$ of the lesions were focal, $21 \%$ diffuse, $26 \%$ proliferative, and $11 \%$ total occlusions. Small vessel size (reference diameter $\leqslant 2.5 \mathrm{~mm}$ ) was present in $49 \%$, long lesions (> $20 \mathrm{~mm}$ ) in $30 \%$, treatment of bypass grafts in $13 \%$, and bifurcation stenting in $18 \%$. At follow up, post-SES restenosis was observed in $14.6 \%$. No restenosis was observed in focal lesions. For more complex lesions, restenosis rates ranged from $20-25 \%$. At the one year follow up, the incidence of death was 0 , myocardial infarction $4.7 \%(n=2)$, and target lesion revascularisation $16.3 \%(n=7)$. The target lesion was revascularised because of restenosis in $11.6 \%(n=5)$.

Conclusions: Routine SES implantation is highly effective for focal in-stent restenosis and appears to be a promising strategy for more complex patterns of restenosis.
\end{abstract}

$\mathrm{D}$ espite major advances in the field of percutaneous coronary interventions, long term outcome is still limited by the occurrence of in-stent restenosis, which has been reported to occur in $10-50 \%$ of the patients in several series. ${ }^{1}$ Furthermore, treatment of in-stent restenosis is often a challenging clinical problem, with recurrent restenosis being reported in up to $80 \%$ in the most complex cases. ${ }^{2}$ Vascular brachytherapy is the only strategy proven to be more effective for the treatment of in-stent restenosis than other conventional approaches. ${ }^{3-7}$ However, post-brachytherapy recurrent restenosis has been reported to occur in $17-32 \%$ of patients at one year. ${ }^{3-7}$ Moreover, despite the relative improvement in outcomes, brachytherapy has not been extensively adopted as routine treatment in many centres, mostly due to logistic and technical limitations.

Sirolimus eluting stents (SES) have been shown in randomised trials virtually to abolish in-stent restenosis in selected patients with de novo lesions. ${ }^{8} 9$ Moreover, prolonged (up to two years) inhibition of the proliferative response has been documented in two series of patients with non-complex lesions. ${ }^{10}{ }^{11}$ Owing to the potent antiproliferative and antimigratory effects of the drug on vascular smooth muscle cells and the clinical efficacy obtained for de novo lesions, SES implantation has been recently tested in two preliminary studies to treat in-stent restenosis. ${ }^{12}{ }^{13}$ In one study with 25 relatively non-complex cases, zero recurrent binary restenosis was observed after SES implantation. ${ }^{13}$ In the other study, among 16 patients with more complex lesions, repeat in-stent restenosis was observed in $20 \%$ of cases. ${ }^{12}$ However, because of the limited number of patients in both reports, the outcome for patients with complex lesion morphology, a condition commonly seen in daily practice, is unclear.

In the present study, we evaluated the clinical and angiographic outcomes of 44 consecutive patients treated with routine SES implantation for in-stent restenosis with a broad range of morphological lesion patterns.

\section{METHODS}

\section{Patient population}

Since 16 April 2002, SES implantation has been adopted as the default strategy for all patients undergoing percutaneous coronary interventions at our institution as part of the RESEARCH (rapamycin eluting stents evaluated at Rotterdam cardiology hospital) registry. ${ }^{14}$ Forty four consecutive patients without previous brachytherapy were treated for in-stent restenosis during a six month enrolment period and constituted the study population. No patient with in-stent restenosis was treated in the same period exclusively with other percutaneous devices (for example, bare metal stents or cutting balloon) or with brachytherapy and therefore was excluded from this report. The study protocol was approved by the hospital ethics committee and is in accordance with the principles of Good Clinical Practice for Trials of Medicinal Products in the European Community and the Declaration of Helsinki. Written informed consent was given by every patient.

Abbreviations: RESEARCH, rapamycin eluting stents evaluated at Rotterdam cardiology hospital; SES, sirolimus eluting stent; TIMI, thrombolysis in myocardial infarction 


\section{Procedure}

The CYPHER SES (Cordis Europa NV, Roden, the Netherlands) was used with all patients. The stents were available in lengths of 8,18 , or $33 \mathrm{~mm}$ and in diameters of $2.25,2.5,2.75$, and $3.0 \mathrm{~mm}$. All procedures were performed according to standard techniques and the final interventional strategy was left to the operator's discretion. Complete lesion coverage was recommended, as well as a small region of overlap of adjacent stents when treating lesions that required more than one stent. Periprocedural adjunctive medications were left to the discretion of the operator. All patients were pretreated with aspirin and clopidogrel. Aspirin was maintained lifelong and at least three months of clopidogrel treatment was recommended thereafter.

\section{Definitions and follow up}

Restenotic lesions were angiographically classified by two independent operators according to the Mehran classification as follows: I, focal ( $<10 \mathrm{~mm}$ ); II, diffuse; III, proliferative; or IV, total occlusion. ${ }^{2}$ A procedure was considered successful when residual stenosis was $<30 \%$ by quantitative coronary analysis with TIMI (thrombolysis in myocardial infarction) flow 3. All patients were requested to undergo an elective repeat angiogram after six months following a successful procedure. Post-SES binary restenosis at follow up was defined as $>50 \%$ diameter stenosis occurring in the segment inside the SES or within a $5 \mathrm{~mm}$ segment proximal or distal to the stent. Late luminal loss was calculated as the difference between the minimum luminal diameter immediately after the procedure and that at six months.

Patients were prospectively followed up to evaluate the incidence of major adverse cardiovascular events, defined as death, myocardial infarction, or target lesion revascularisation. Target lesion revascularisation was defined as any surgical or percutaneous reintervention motivated by a significant luminal narrowing within the stent or in the $5 \mathrm{~mm}$ distal or proximal peristent segments.

\section{Statistical analysis}

Discrete variables are reported as counts and relative percentages and compared by Fisher's exact test. Continuous variables are expressed as mean (SD) and compared by Student's $t$ test. A probability value of $\mathrm{p}<0.05$ was considered to be significant. All tests were two tailed. Analyses were performed with the SPSS version 8.0 statistical package (SPSS Inc, Chicago, Illinois, USA).

\section{RESULTS}

\section{Baseline and procedural data}

Table 1 shows baseline clinical characteristics of the 44 patients with in-stent restenosis. Diabetes was present in 25\% of the patients. Clinical presentation was an acute coronary syndrome in $27 \%$ of patients. A quarter of the patients had previous recurrent episodes of in-stent restenosis. According to the Mehran classification, $42 \%$ of the lesions were class I, $21 \%$ class II, $26 \%$ class III, and $11 \%$ class IV (table 2 ). Small vessel size (reference diameter $\leqslant 2.5 \mathrm{~mm}$ ) was present in $49 \%$, long lesions (>20 mm) in $30 \%$, treatment of bypass grafts in $13 \%$, and bifurcation stenting in $18 \%$. The patients received on average (SD) 2.0 (1.4) stents, with a mean (SD) stent length per lesion of 28 (20) mm (range 8-84 mm). Direct stenting was performed in 13 lesions $(24.5 \%)$. Seven lesions (13.2\%) were predilated with a cutting balloon. Endovascular ultrasound was used in $25 \%$ of the procedures for stent sizing or to optimise the result. The procedure was successful in 43 patients $(97.7 \%)$. One patient underwent emergency bypass surgery due to intimal dissection and acute vessel occlusion during the procedure.

\section{Table 1 Baseline patient characteristics}

Number of patients

Mean (SD) age (years)

Men

Risk factors

Current smoker

Hypercholesterolaemia*

Systemic hypertension

Diabetes mellitus

Family history of coronary heart disease

Clinical presentation

Silent ischaemia

Stable angina pectoris

Unstable angina pectoris

Acute myocardial infarction

Multivessel coronary disease

Previous myocardial infarction

Previous coronary bypass

Recurrent episodes of in-stent restenosis (> 1)

44

$63(13)$

$73 \%$

$27 \%$

$68 \%$

$48 \%$

$25 \%$

$43 \%$

$9 \%$

$64 \%$

$64 \%$
$25 \%$
$2 \%$

$50 \%$

$52 \%$

$23 \%$

*Total cholesterol $>5.2 \mathrm{mmol} / \mathrm{l}$ or taking lipid lowering drugs.

\section{Table 2 Angiographic and procedural characteristics}

\begin{tabular}{ll}
\hline Number of lesions & 53 \\
Target coronary artery & \\
$\quad$ Left anterior descending & $49 \%$ \\
Left circumflex artery & $11 \%$ \\
Right coronary artery & $26 \%$ \\
Left main & $2 \%$ \\
Saphenous vein graft & $9 \%$ \\
Left internal mammary artery & $2 \%$ \\
Mehran class & \\
I (focal) & $42 \%$ \\
II (diffuse) & $21 \%$ \\
III (proliferative) & $26 \%$ \\
IV (total occlusion) & $11 \%$ \\
Small vessel size* & $49 \%$ \\
Bifurcation stenting† & $18 \%$ \\
Multivessel stentingt & $25 \%$ \\
Glycoprotein Ilb/llla inhibitors $\dagger$ & $9 \%$ \\
Mean (SD) stent length per lesion (mm) & $28(20)$ \\
Mean (SD) stents per patient & $2.0(1.4)$ \\
\hline *Preprocedure reference diameter $\leqslant 2.5$ mm; tpercentages relative to \\
the number of patients.
\end{tabular}

\section{Angiographic results}

Table 3 shows the preprocedure, post-procedure, and follow up quantitative angiographic data. Figure 1 shows representative sequences of angiograms from two patients. Mean (SD) reference diameter was $2.64(0.56) \mathrm{mm}$ and mean lesion length was 17.5 (12.1) mm. Angiographic follow up was obtained from 33 patients $(77 \%$ of patients with a successful index procedure) with 41 lesions (79\%). Late loss was $0.17(0.76) \mathrm{mm}$. Cumulative distribution curves of angiographic late loss (fig 2) show that the vast majority of the lesions $(79 \%)$ had a late loss between -0.5 and $0.5 \mathrm{~mm}$. Overall, post-SES binary restenosis was observed in $14.6 \%$ of the lesions. Table 4 shows the frequency of post-SES restenosis for some subgroups. No restenosis was observed in Mehran class I lesions; $22 \%$ of class II, $25 \%$ of class III, and $20 \%$ of class IV lesions had post-SES restenosis (not significant). In five of six cases of post-SES restenosis the restenosis was focal or multifocal. For patients with post-SES restenosis, the average lesion length decreased from 31.7 (15.3) $\mathrm{mm}$ at baseline to $10.0(4.8) \mathrm{mm}$ at follow up $(\mathrm{p}=0.01)$. One patient presented after SES implantation with silent total occlusion. Post-SES restenotic lesions were located within the SES in five lesions and at the proximal edge in the remaining one. In two patients, post-SES restenosis occurred in an uncovered region injured during the procedure (a gap between two SES implanted to treat two 
Table 3 Quantitative angiographic analysis at baseline, post-procedure, and follow up*

\begin{tabular}{llll}
\hline & Preprocedure & Post-procedure & Follow up \\
\hline Reference diameter $(\mathrm{mm})$ & $2.64(0.56)$ & $2.73(0.54)$ & $2.83(0.50)$ \\
Minimum lumen diameter $(\mathrm{mm})$ & $0.90(0.55)$ & $2.33(0.59)$ & $2.20(0.81)$ \\
Diameter stenosis (\%) & $66(19)$ & $16(15)$ & $23(25)$ \\
Lesion length $(\mathrm{mm})$ & $17.5(12.1)$ & $\mathrm{NA}$ & $\mathrm{NA}$ \\
Acute gain $(\mathrm{mm})$ & $\mathrm{NA}$ & $1.42(0.70)$ & $\mathrm{NA}$ \\
Late loss $(\mathrm{mm})$ & $\mathrm{NA}$ & $\mathrm{NA}$ & $0.17(0.76)$ \\
Late loss excluding occlusions $(\mathrm{mm})$ & $\mathrm{NA}$ & $\mathrm{NA}$ & $0.11(0.67)$ \\
Binary post-SES restenosis† & $\mathrm{NA}$ & $\mathrm{NA}$ & $14.6 \%$ \\
\hline
\end{tabular}

Data are mean (SD).

*Related to 41 lesions with angiographic follow up; tincluding one total reocclusion.

NA, not applicable; SES, sirolimus eluting stent.

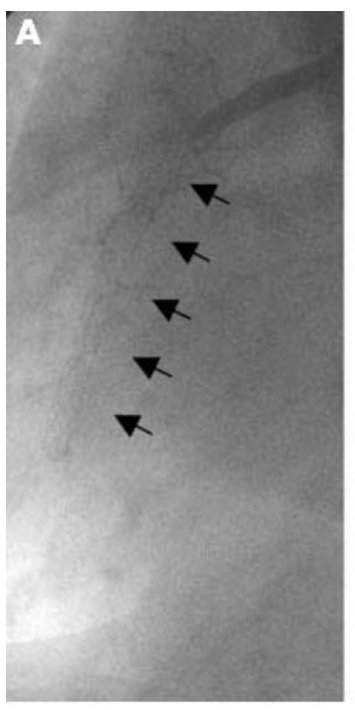

D

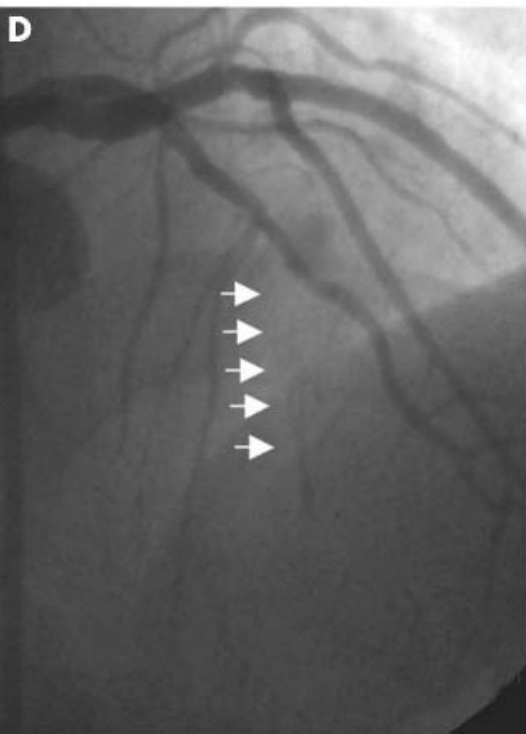

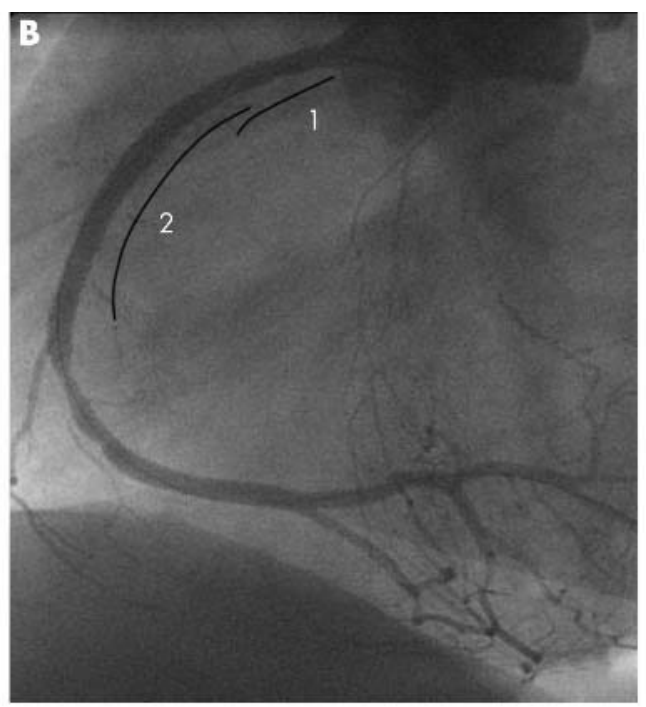

E

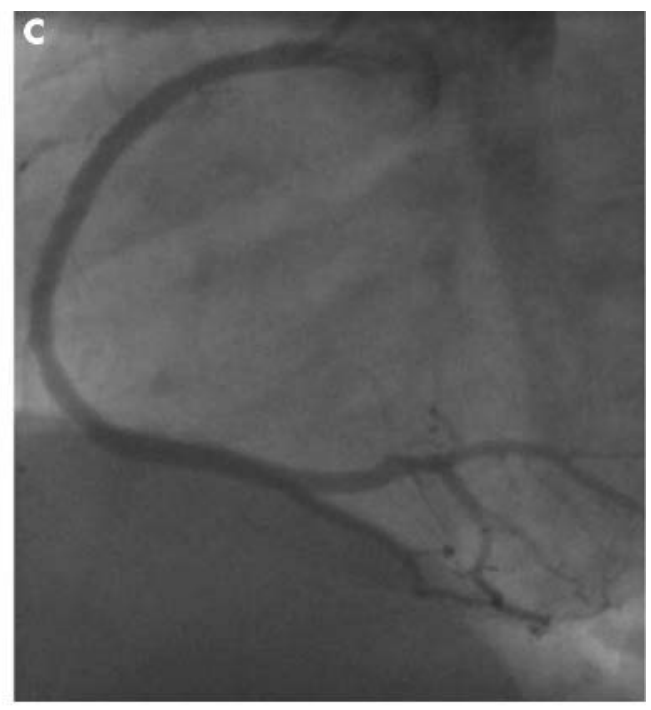

$\mathbf{F}$
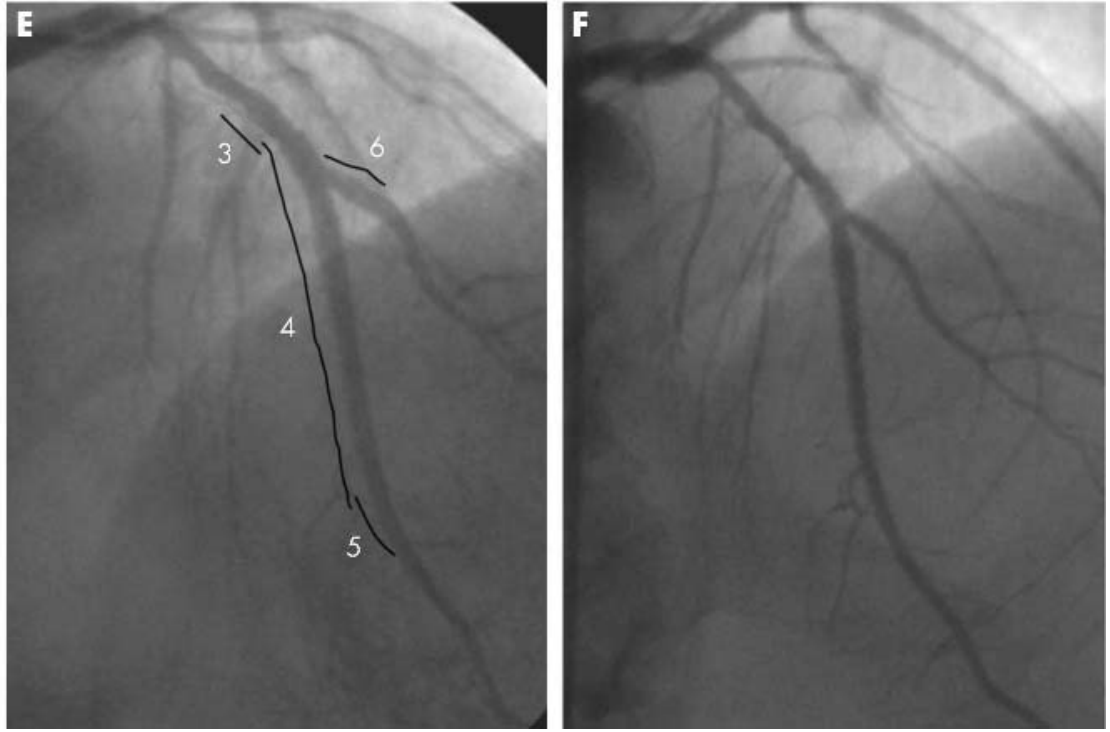

Figure 1 Sirolimus eluting stent (SES) implantation for total occlusion due to in-stent restenosis: representative sequences of angiograms from two patients. Patient 1: (A) Diagnostic angiogram showing total occlusion of the proximal right coronary artery due to in-stent restenosis (arrows). (B) Final result after implantation of two overlapping SES, $3 \times 18 \mathrm{~mm}$ proximal (1), and $3 \times 33 \mathrm{~mm}$ distal (2). Some minimal residual stenosis is visible at the distal stent edge. (C) Six month angiographic follow up showing persistence of the good result obtained previously. Patient 2: (D) Diagnostic angiogram showing in-stent restenosis giving total occlusion of the mid part of the left anterior descending artery (LAD) (arrows), immediately after the origin of the second diagonal branch. (E) Final result after implantation of three overlapping SES in the LAD, $2.75 \times 8 \mathrm{~mm}$ proximal (3), $2.5 \times 33 \mathrm{~mm}$ in the middle (4), and $2.25 \times 8 \mathrm{~mm}$ distal (5). Bifurcation stenting was necessary to preserve the second diagonal (6, SES $2.25 \times 8 \mathrm{~mm})$. (F) Six month angiographic follow up showing persistence of the good result in both vessels. 


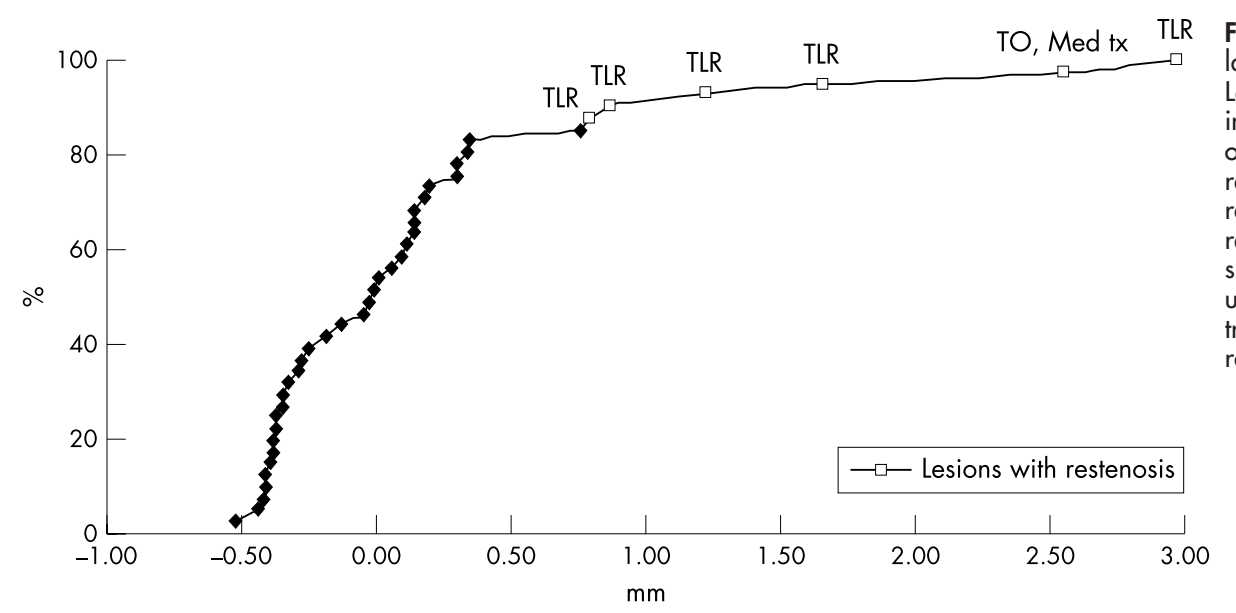

Figure 2 Cumulative distribution of late loss at angiographic follow up. Lesions with binary restenosis are indicated by empty squares. Clinical outcome of each restenotic lesion is reported corresponding to the respective late loss value. This curve resembles a bimodal distribution and suggests that the failed cases may share unique features. Med tx, medical treatment; TLR, target vessel revascularisation; $\mathrm{TO}$, total occlusion.

separate lesions in one patient and stent discontinuity by ultrasound examination due to possible stent fracture in another patient). ${ }^{15}$ Major SES undersizing (stent diameter $2.7 \mathrm{~mm}$; vessel diameter $5.7 \mathrm{~mm}$ ) was found in another patient with post-SES restenosis.

The patients who developed post-SES restenosis had baseline clinical characteristics similar to the others. However, the lesions that developed binary restenosis were considerably longer (29.1 (15.0) $\mathrm{mm} v 16.1$ (11.0) mm, $\mathrm{p}=0.01)$ and were treated with more stents $(2.2(0.7) v$ $1.5(0.7), p=0.04)$. The stented segment was longer (average stent length per lesion 49.0 (30.0) mm $v 25.5$ (16.3) $\mathrm{mm}, \mathrm{p}<0.01$ ) than lesions that had less than $50 \%$ diameter stenosis at follow up.

\section{Clinical follow up}

Complete clinical follow up was available for 43 patients (98\%). After one year, the cumulative incidence of major adverse cardiovascular events was $20.9 \%$. There were no deaths, two patients had non-Q wave myocardial infarction $(4.7 \%)$ - of which one occurred periprocedurally and one after seven months - and seven patients (16.3\%) underwent target lesion revascularisation (including the patient who underwent emergency coronary artery bypass grafting). The target lesion was revascularised because of restenosis in five patients (11.6\%). One additional target lesion was revascularised five days after the index procedure in a patient with recurrent angina and intravascular ultrasound evidence of incomplete right coronary artery ostium coverage. All repeat revascularisations were within seven months' follow up.

\begin{tabular}{|c|c|c|}
\hline & $\begin{array}{l}\text { Lesions with } \\
\text { angiographic } \\
\text { follow up }\end{array}$ & $\begin{array}{l}\text { Post-SES } \\
\text { restenosis }\end{array}$ \\
\hline Total population & 41 & $14.6 \%$ \\
\hline Diabetics & 8 & $25.0 \%$ \\
\hline Small vessel size† & 20 & $10.0 \%$ \\
\hline Vein grafts & 5 & $20.0 \%$ \\
\hline Lesion length $>20 \mathrm{~mm}$ & 14 & $28.6 \%$ \\
\hline Bifurcating stents $\ddagger$ & 7 & $14.3 \%$ \\
\hline \multicolumn{3}{|l|}{ Mehran class ${ }^{2}$} \\
\hline I (focal) & 15 & 0 \\
\hline II (diffuse) & 9 & $22.2 \%$ \\
\hline III (proliferative) & 12 & $25.0 \%$ \\
\hline IV (total occlusion) & 5 & $20.0 \%$ \\
\hline \multicolumn{3}{|c|}{$\begin{array}{l}\text { *Related to } 41 \text { lesions with angiographic follow up. } \\
\text { †reprocedure reference diameter } \leqslant 2.5 \mathrm{~mm} \text {. } \\
\text { tRefers only to the in-stent restenosis lesions - in these series, there was } \\
\text { no case of restenosis in the side branches treated for de novo lesions. }\end{array}$} \\
\hline
\end{tabular}

There were no documented episodes of early or late stent thromboses. It is worth noting that patients who refused to undergo angiographic re-evaluation had no adverse events during follow up.

\section{DISCUSSION}

The major finding of the present study is that routine SES implantation for in-stent restenosis is safe and associated with low recurrence rates in a broad range of clinical and anatomical settings.

The present series comprises patients and lesions commonly not examined in previous reports, ${ }^{12}{ }^{13} 16$ such as very long lesions, chronic total occlusions, small vessels, bypass grafts, and bifurcations. In fact, the majority of patients in our consecutive series, representative of the everyday practice, had at least one of the aforementioned characteristics. Despite the unselected nature of this population, clinical and angiographic outcomes appear superior to previous results with conventional approaches. ${ }^{217-21}$ Indeed, our findings compare favourably with those reported for vascular brachytherapy, which has been advocated as the treatment of choice for complex in-stent restenosis. ${ }^{3-7}$ Moreover, SES implantation does not deviate from practice with conventional bare stents and avoids most of the technical and logistical limitations that have hampered a more widespread use of brachytherapy.

The outcomes of patients with in-stent restenosis after repeat treatment have been reported to be closely related to the baseline lesion morphology. ${ }^{2}$ The risk profile increases progressively from lesions with a focal pattern to lesions with a more diffuse appearance and total occlusions. ${ }^{2}$ Accordingly, in our series, SES implantation was associated with a remarkably low incidence of recurrent restenosis in focal lesions. Indeed, all cases of repeat restenosis occurred in patients with more complex baseline characteristics. However, no clear differences in the rates of repeat restenosis were noted among higher risk categories (that is, Mehran classes II, III, and IV), in which the rates of repeat restenosis have been reported to be $35 \%, 50 \%$, and $85 \%$, respectively, with conventional treatment. Thus, it is possible that SES implantation reduces the prognostic value of the lesion pattern of in-stent restenoses for non-focal in-stent restenosis, although the limited number of our observations does not allow a definitive conclusion. Conversely, our data suggest that lesion length may still have an impact on recurrent restenosis. Recently, SES have been consistently shown to reduce neointimal proliferation in in-stent restenosis as effectively as in de novo lesions. ${ }^{21}$ Instead of reflecting an intrinsic drug resistance, repeat restenosis in complex lesions may actually be more closely related to local 
Table 5 Drug eluting stent implantation for in-stent restenosis: angiographic results of the principal studies

\begin{tabular}{|c|c|c|c|c|c|c|}
\hline & TAXUS-1II ${ }^{16}$ & FIM-Rotterdam ${ }^{12}$ & \multicolumn{2}{|c|}{ FIM-São Paulo ${ }^{13}$} & $\begin{array}{l}\text { ISR post- } \\
\text { brachytherapy }{ }^{24}\end{array}$ & RESEARCH registry \\
\hline Drug & Paclitaxel & Sirolimus & \multicolumn{2}{|l|}{ Sirolimus } & Sirolimus & Sirolimus \\
\hline Patients & 28 & 16 & \multirow{2}{*}{\multicolumn{2}{|c|}{$\begin{array}{l}25 \\
\text { Single lesion; native coronary } \\
\text { artery; vessel size } 2.5-3.5 \mathrm{~mm}\end{array}$}} & 12 & 44 \\
\hline Inclusion criteria & $\begin{array}{l}\text { Single lesion, native } \\
\text { coronary artery; vessel } \\
\text { size } 3.0-3.5 \mathrm{~mm}\end{array}$ & $\begin{array}{l}\text { Single lesion; native } \\
\text { coronary artery; vessel } \\
\text { size } 2.5-3.5 \mathrm{~mm}\end{array}$ & & & $\begin{array}{l}\text { Previous } \\
\text { brachytherapy }\end{array}$ & $\begin{array}{l}\text { All clinical and } \\
\text { anatomical } \\
\text { conditions }\end{array}$ \\
\hline Exclusion criteria & $\begin{array}{l}\text { Acute myocardial } \\
\text { infarction; lesion length } \\
>30 \mathrm{~mm} \text {; total occlusion; } \\
\text { LVEF }<30 \% \text {; renal } \\
\text { dysfunction }\end{array}$ & Saphenous vein graft & \multicolumn{2}{|c|}{$\begin{array}{l}\text { Previous brachytherapy; lesion } \\
\text { length }>36 \mathrm{~mm} \text {; total occlusion }\end{array}$} & NA & $\begin{array}{l}\text { Previous } \\
\text { brachytherapy }\end{array}$ \\
\hline Reference diameter $(\mathrm{mm})$ & $2.75(1.20)$ & $2.68(0.33)$ & \multirow{3}{*}{\multicolumn{2}{|c|}{$\begin{array}{l}2.78(0.30) \\
13.6(7.65) \\
22(7)\end{array}$}} & $2.83(0.48)$ & $2.64(0.56)$ \\
\hline Lesion length $(\mathrm{mm})$ & $13.6(6.4)$ & $18.4(13.1)$ & & & NA & $17.5(12.1)$ \\
\hline Stent length $(\mathrm{mm})$ & $22(8)$ & $28(18)$ & & & $34(30)$ & $28(20)$ \\
\hline Time of follow up (months) & 6 & 6 & 4 & 12 & 6 & 6 \\
\hline Late loss $(\mathrm{mm})^{*}$ & $0.54(0.51) \dagger$ & $0.26(0.67)$ & $-0.05(0.30)$ & $0.16(0.42)$ & $0.68(1.2)$ & 0.1710 .760 \\
\hline Binary restenosis* & $16.0 \%$ & $20.0 \%$ & $0 \%$ & $4.0 \%$ & $40.0 \%$ & $14.6 \%$ \\
\hline
\end{tabular}

*In-stent plus $5 \mathrm{~mm}$ segment proximal and distal to the stent; tin-stent only.

ISR, in-stent restenosis; LVEF, left ventricular ejection fraction; RESEARCH, rapamycin eluting stent evaluated at Rotterdam cardiology hospital.

mechanical conditions that impair the treatment effect of the device (that is, incomplete coverage of balloon injured areas of neointimal hyperplasia or underexpanded stents). In fact, a possible technical reason for failure was documented in three of six cases $(50 \%)$ of recurrent restenosis in our series, although the significance of these findings remains elusive. Two recent reports have confirmed these observations in a larger number of patients treated with SES. ${ }^{22}{ }^{23}$

This study evaluated a relatively limited number of patients and lesions. However, this is the largest series of patients described to date (table 5). Moreover, to the best of our knowledge, this is the first study to assess the impact of SES implantation in a broad range of different anatomical subsets of in-stent restenosis.

The rate of angiographic follow up (79\% of all lesions), although similar to that of other studies that enrolled patients with recurrent in-stent restenosis, ${ }^{367}$ is not very high and is insufficient to allow for determination of the true binary restenosis rate for the entire cohort. This may be explained by the considerable numbers of recurrent restenoses and previous procedures among some patients, who were therefore not willing to undergo a six month angiography in the absence of symptoms. This was indirectly confirmed by the clinical follow up of the patients who refused the angiographic control, who were all asymptomatic. Patients with failed brachytherapy were not included in the current report. We have recently shown that recurrent in-stent restenosis after vascular brachytherapy may exhibit a peculiar and different biological and clinical response to SES implantation ${ }^{24}$ and is therefore a potentially confounding factor if analysed conjointly with data for patients without prior local irradiation.

\section{Conclusions}

Routine use of SES implantation to treat in-stent restenosis appeared safe and effective in an unselected series of cases of in-stent restenosis, especially among patients with focal lesions. SES implantation also seems to be a promising strategy for complex in-stent restenosis. Further analysis with larger series and more prolonged follow up, as well as a direct comparison with brachytherapy in a randomised fashion, is needed to clarify the role of SES in this context.

\section{ACKNOWLEDGEMENTS}

This study was supported by health care funds allotted by Erasmus Medical Centre (Erasmus University), Rotterdam, the Netherlands, and by an institutional research grant from Cordis Corporation, a
Johnson \& Johnson Company, Miami Lakes, Florida, USA. Cordis Corporation did not have any role in the collection, management, and analysis of the data.

The authors thank Dr Brian Firth for his critical review of the manuscript.

\section{Authors' affiliations}

F Saia, P A Lemos, C A Arampatzis, A Hoye, M Degertekin, K Tanabe, G Sianos, P C Smits, W J van der Giessen, P J de Feyter, R T van Domburg, P W Serruys, Department of Invasive Cardiology,

Thoraxcentre, Erasmus University Medical Centre, Rotterdam, the Netherlands

\section{REFERENCES}

1 Lowe HC, Oesterle SN, Khachigian LM. Coronary in-stent restenosis: current status and future strategies. J Am Coll Cardiol 2002;39:183-93.

2 Mehran R, Dangas G, Abizaid AS, et al. Angiographic patterns of in-stent restenosis: classification and implications for long-term outcome. Circulation 1999; 100:1872-8.

3 Leon MB, Teirstein PS, Moses JW, et al. Localized intracoronary gammaradiation therapy to inhibit the recurrence of restenosis after stenting. N Engl J Med 2001;344:250-6.

4 Teirstein PS, Massullo V, Jani S, et al. Catheter-based radiotherapy to inhibit restenosis after coronary stenting. N Engl J Med 1997;336:1697-703.

5 Waksman R, White RL, Chan RC, et al. Intracoronary gamma-radiation therapy after angioplasty inhibits recurrence in patients with in-stent restenosis. Circulation 2000;101:2165-71.

6 Waksman R, Bhargava B, White L, et al. Intracoronary beta-radiation therapy inhibits recurrence of in-stent restenosis. Circulation 2000;101:1895-8.

7 Waksman R, Raizner AE, Yeung AC, on behalf of the INHIBIT investigators, et al. Use of localised intracoronary $\beta$ radiation in the treatment of in-stent restenosis: the INHIBIT randomised controlled trial. Lancet 2002;359:551-7.

8 Morice MC, Serruys PW, Sousa JE, et al. A randomized comparison of a sirolimus-eluting stent with a standard stent for coronary revascularisation. N Engl J Med 2002;346:1773-80.

9 Moses JW, Leon MB, Popma JJ, et al. Angiographic and clinical outcomes after a sirolimus-eluting stent compared to a standard stent in patients with native coronary artery stenoses. N Engl J Med 2003;349:1315-23.

10 Degertekin M, Serruys PW, Foley DP, et al. Persistent inhibition of neointimal hyperplasia after sirolimus-eluting stent implantation: long-term (up to 2 years) clinical, angiographic, and intravascular ultrasound follow-up. Circulation 2002; 106:1610-3.

11 Sousa JE, Costa MA, Sousa AG, et al. Two-year angiographic and intravascular ultrasound follow-up after implantation of sirolimus-eluting stents in human coronary arteries. Circulation 2003;107:381-3.

12 Degertekin M, Regar E, Tanabe K, et al. Sirolimus-eluting stent for treatment of complex in-stent restenosis: the first clinical experience. J Am Coll Cardiol 2003;41:184-9.

13 Sousa JE, Costa MA, Abizaid A, et al. Sirolimus-eluting stent for the treatment of in-stent restenosis: a quantitative coronary angiography and threedimensional intravascular ultrasound study. Circulation 2003;107:24-7.

14 Lemos PA, Lee CH, Degertekin M, et al. Early outcome after sirolimus-eluting stent implantation in patients with acute coronary syndromes: insights from the rapamycin-eluting stent evaluated at Rotterdam Cardiology Hospital (RESEARCH) registry. J Am Coll Cardiol 2003;41:2093-9.

15 Sianos G, Hofma S, Ligthart J, et al. Stent fracture in the drug-eluting stent era. Catheter Cardiovasc Interv 2004;61:111-6. 
16 Tanabe K, Serruys PW, Grube E, et al. TAXUS III trial. In-stent restenosis treated with stent-based delivery of paclitaxel incorporated in a slow-release polymer formulation. Circulation 2003; 107:559-64.

17 Adamian M, Colombo A, Briguori C, et al. Cutting balloon angioplasty for the treatment of in-stent restenosis: a matched comparison with rotationa atherectomy, additional stent implantation and balloon angioplasty. J Am Coll Cardiol 2001;38:672-9.

18 Alfonso F, Cequier A, Zueco J, et al. Stenting the stent: initial results and long term clinical and angiographic outcome of coronary stenting for patients with in-stent restenosis. Am J Cardiol 2000:85:327-32.

19 Giri S, Ito S, Lansky AJ, et al. Clinical and angiographic outcome in the laser angioplasty for restenotic stents (LARS) multicenter registry. Catheter Cardiovasc Interv 2001;52:24-34.

20 Vom Dahl J, Dietz U, Haager PK, et al. Rotational atherectomy does not reduce recurrent in-stent restenosis: results of the angioplasty versus rotational atherectomy for treatment of diffuse in-stent restenosis trial (ARTIST). Circulation 2002; 105:583-8.

21 Degertekin $M$, Lemos PA, Lee $\mathrm{CH}$, et al. Intravascular ultrasound evaluation after sirolimus eluting stent implantation for de novo and in-stent restenosis lesions. Eur Heart J 2004:25:32-8.

22 Colombo A, Orlic D, Stankovic G, et al. Preliminary observations regarding angiographic pattern of restenosis after rapamycin-eluting stent implantation. Circulation 2003;107:2178-80.

23 Lemos PA, Saia F, Ligthart JM, et al. Coronary restenosis after sirolimus-eluting stent implantation: morphological description and mechanistic analysis from a consecutive series of cases. Circulation 2003; 108:257-60.

24 Saia F, Lemos PA, Sianos G, et al. Effectiveness of sirolimus-eluting stent implantation for recurrent in-stent restenosis after brachytherapy. Am J Cardiol 2003;92:200-3.

\section{IMAGES IN CARDIOLOGY}

\section{An anomalous right coronary artery shown by multislice CT coronary angiography}

A 78 year old woman presented to hospital with chest pain and anterior $\mathrm{T}$ wave changes. She was started on clexane, intravenous (iv) nitrate, and iv tirofiban, and transferred for inpatient cardiac catheterisation. The proximal left anterior descending (LAD) coronary artery showed a subtotal lesion, however the right coronary artery (RCA) could not be cannulated by an experienced operator. The aortogram showed flow into a small atypical RCA, and the distal RCA was shown by collaterals from the LAD. In view of the development of a large groin haematoma and no recent chest pain, percutaneous coronary intervention to the LAD was deferred and a multislice computed tomography (MSCT) coronary angiogram was arranged to exclude an ostial RCA lesion.

MSCT coronary angiogram (Sensation 16, Siemens, Germany) was performed using an ECG gated standard protocol. An atypical RCA was demonstrated originating from the left sinus of Valsalva. It was small in overall diameter $(1.2 \mathrm{~mm})$ and passed between the aorta and pulmonary artery before following a standard course in the right

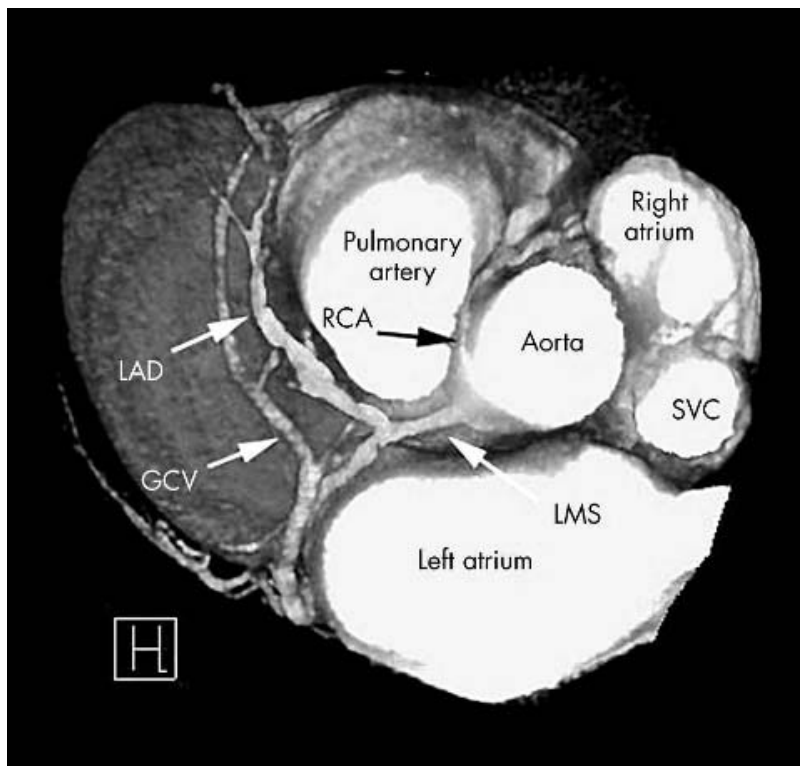

Three dimensional volume reconstruction superior clip plane view of anomalous right coronary artery (RCA) (black arrow). LMS, left main stem; LAD, left anterior descending artery; GCV, great cardiac vein; SVC, superior vena cava. atrioventricular groove. The atypical origin and initial course is shown (black arrows) in the left hand panel by a superiorly applied clip plane to a three dimensional volume reconstruction; it also shown in the right hand panel in an anterolateral three dimensional volume reconstruction with the obscuring pulmonary artery edited along with parts of the proximal LAD.

In this case, the aortogram suggested a posterior origin of the RCA. However, MSCT shows the atypical origin, with initial compression, followed by an increase in calibre of the aberrant vessel.

R Coles

P Wilde

A Baumbach D.R.Coles@bristol.ac.uk

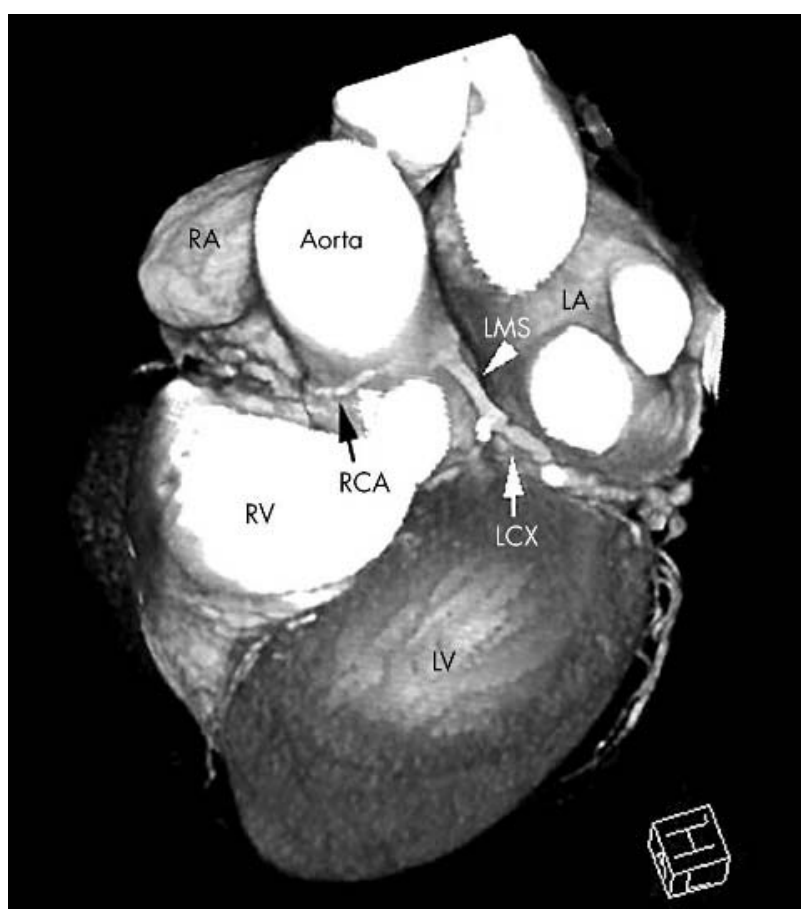

Anterolateral three dimensional volume reconstruction view of anomalous RCA (black arrow). LMS, left main stem; LCX, left circumflex artery; LA, left atrium; LV, left ventricle; RA, right atrium; RV, right ventricle. 